\section{Lo cotidiano como lugar en disputa en los territorios forestales chilenos. Entre dinámicas globales, dispositivos estatales y prácticas populares*}

\section{The everyday life as a dispute place in the Chilean forestry territories. Between global dynamics, state devices and popular practices}

\author{
Massimiliano FaRRIS \\ Marcela Salgado ${ }^{* * *}$
}

El artículo se desprende del proyecto de investigación FONDECYT Postdoctorado $n^{\circ} 3160767$ (I.R. Massimiliano Farris) y CONICYT PIA SOC 1404 (Doctorante Marcela Salgado).

** Universidad de Chile, Portugal 84, Santiago; massimilianof@ uchilefau.cl

*** Doctorante Universidad de Chile, salgado.marcela@gmail.com

\section{Resumen}

Las reflexiones teóricas sobre la importancia del espacio de la cotidianidad nos han permitido acercarnos al estudio de las relaciones de poder en los territorios forestales de Chile desde una perspectiva transescalar, evidenciando la dialéctica entre el despliegue de prácticas de hegemonía territorial por parte de las grandes empresas forestales y los mecanismos de adaptación /resistencia a ello por parte de algunos grupos sociales.

Se presentan dos casos de estudio. El primero en la región del Maule aborda las estrategias de una empresa forestal en producir/resignificar, controlar y dirigir prácticas cotidianas de la población local después de dos acontecimientos disruptivos (terremoto 2010 e incendios 2017). El otro, en la región de Ñuble evidencia la permanencia de prácticas productivas vitivinícolas tradicionales que conforman la cotidianidad territorial del valle del Itata desde siglos y aparecen "resistentes/resilientes" tanto a la gran industria del vino chilena como a la expansión forestal.

Palabras clave: industria forestal, hegemonía territorial, valor compartido, geopolítica del cotidiano, Chile

\section{Abstract}

The theoretical approaches about the importance of the space of every-day life have allowed us to approach the study of the power relationship in the forest territories of Chile from a transcalar perspective, evidencing the dialectic between the deployment of practices 
of territorial hegemony by forestry holding and the mechanisms of resilience / resistance to it by some social local groups. Two case studies are presented. The first, in the Maule region, addresses the strategies of a forestry company to produce / resignify, control and direct the every-day life practices of the local population after two disruptive events (earthquake 2010 and forest fire 2017). The other, in the Nuble region, demonstrates the permanence of traditional winemaking practices that make up the territorial daily life of the Valle del Itata for centuries and appear "resistant / resilient" to the Chilean wine industry as the forest expansion.

Key words: forest industry, territorial hegemony, shared value, every-day life geopolitics, Chile

\section{Introducción}

La plantación de especies arbóreas exóticas para uso productivo en Chile comienza en 1830, pero es Federico Albert, gracias a sus estudios desarrollados a finales del siglo XIX, quien promueve la forestación estatal de los cerros con el objeto de detener la erosión de los suelos causada por la producción intensiva de cereales en el sistema de latifundio - y proveer de madera y combustible a los centros urbanos y actividades industriales (Camus 2006; Prado 2015).

El Estado ha jugado un importante rol en la conformación de una institucionalidad enfocada en la protección y fomento de la actividad forestal. Ha desarrollado, así, un proceso de "modernización" de las actividades forestales y madereras que deja en evidencia que la lucha contra la erosión a través de la forestación tenía un doble propósito: conservar las tierras $\mathrm{y}$, conformar y consolidar un área productiva destinada a sustituir el sistema agrario en crisis (Camus 2006).

Con la dictadura militar, el Estado sigue teniendo un rol central en el fomento del sector forestal, imprimiéndole un cambio ideológico y estructural significativo: desde una gestión pública a una privada. El hito central de esta transformación ha sido la promulgación del Decreto Ley 701 de 1974 con el cual el Estado incentiva la inversión privada orientada a la plantación de especies exóticas. Este instrumento generó dos efectos de largo alcance: una explosiva forestación y una nueva gran concentración de la tierra. De modo que, desde finales de la década de 1980, sólo dos grupos económicos poseían la mayoría de las plantas productivas de celulosa y de superficie forestada, concentrando los procesosindustriales, la tierra y el capital en las mismas manos (Canals 2014). Al respecto, de acuerdo con lo planteado por Canals (2014), el proceso de concentración se dio por los mecanismos de oligopsonio y oligopolio que operaron las grandes empresas forestales. En este sentido, estas empresas no sólo controlan gran parte de las plantaciones $\mathrm{y}$, por ende, la oferta de trozas, sino que también las industrias, permitiéndoles determinar los precios y desbaratar la competencia.

El sector forestal se presenta entonces como una clara expresión del "capitalismo familiar" que se ha desarrollado y consolidado en el país, desde el golpe militar de 1973, caracterizándose como extremadamente concentrado en pocos grandes grupos económicos (holding) que controlan el conjunto de la economía de forma oligopolista (Fazio 2005, 2016; Atienza et al. 2015; Undurraga 2014).

Arauco S.A. del Grupo Antar Chile, controlada por la familia Angelini, y la Compañía 
Manufacturera de Papeles y Cartones (CMPC), controlada por la familia Matte, son los dos principales grupos del sector. Estas sociedades concentran tanto la propiedad de la materia prima, como de la industria de transformación, lo cual les permite dominar las exportaciones. Esto evidencia el rol hegemónico de estos dos grandes grupos que controlan el mercado local, en el cual el espacio para que las pequeñas empresas se puedan insertar es limitado a actividades secundarias (postes o aserraderos móviles). Esta concentración se refleja también en términos territoriales: el sector se presenta como un cluster productivo ubicado entre el $34^{\circ} \mathrm{y}$ el $38^{\circ}$ paralelo sur, aunque es en las regiones del Maule y del Biobío donde se localiza la mayoría de la superficie plantada y de las industrias.

En consideración de este desarrollo que ha tenido el sector forestal, en particular su concentración económica y territorial, nos planteamos el objetivo de analizar cómo se ha dado el proceso de territorialización y cuáles han sido las implicaciones sobre la cotidianidad. En específico, nos hemos enfocado en plantear unas posibles respuestas, desde los territorios forestales, a unas preguntas de este dossier, a saber:

¿Cómo se puede conectar las escalas/espacios/ agentes geopolíticas en la investigación? ¿Cómo se puede investigar la geopolítica del Estado y la geopolítica de la cotidianeidad?

\section{Técnica, cotidianidad y hegemonía como claves analíticas de la territorialización de las regiones forestales.}

La expansión de las plantaciones forestales ha significado una profunda transformación de los territorios en diferentes escalas tanto espaciales como temporales. Cotidianidad y territorialidad son conceptos estrechamente vinculados entre si y resultan centrales para entender estos procesos.

A este propósito, los planteamientos de Milton Santos (2000) son esclarecedores. Él evidencia como Espacio (y Lugar) están íntimamente relacionados con el tiempo. La construcción del espacio es un proceso constante que se desarrolla en el tiempo a través de la aplicación de técnicas diferentes en función de cada época histórica. Cada técnica es el resultado de la dialéctica entre dos sistemas: de acciones, desplegadas por los seres humanos, y de objetos. La relación dialéctica entre estos dos sistemas, que determina el territorio y su evolución en el tiempo, se puede considerar como la territorialidad. Es importante dejar presente que cualquier modificación en uno de estos sistemas redefine a la vez ambos. La inserción de un nuevo "objeto" en el sistema redefine también el sistema de acciones. Este proceso constante construye el Espacio como Totalidad. El Lugar es una porción del Espacio y se configura como un híbrido de sistema de objetos y sistema de acciones, determinado por condiciones particulares que se dan en momentos específicos a través de la combinación de acciones y objetos. Santos plantea tres factores que determinan la peculiaridad del lugar: la cotidianidad, la proximidad y la cultura. Lo que nos entrega esta visión del territorio es que incidir sobre estas dimensiones significa determinar qué construcción del espacio se quiere realizar. La construcción del Espacio se da incidiendo en las prácticas "banales" de todos los días y en las relaciones sociales que se consolidan en el tiempo en un determinado ambiente. $Y$ tal 
como se crea, se pueden destruir: cambiando el sistema de acciones o insertando uno o más objetos nuevos en ese ambiente.

Lo descrito anteriormente, no es un proceso neutral: los cambios en el sistema de acciones y objetos responden a las transformaciones en las relaciones de poder entre actores que ocupan un lugar que se va modificando en el tiempo en relación a los intereses de estos actores. Al respecto, Sevilla (2014) recurre a la noción de territorialidad para comprender el modo en que los fenómenos espaciales se filtran en la conformación de lo cotidiano. En este sentido, la territorialidad se relaciona con la estrategia en la que un sujeto o grupo traza su proyecto de influencia y dominio sobre otros grupos de población por medios indirectos, instrumentalizando el espacio para dichos fines. Desde esta lectura, el espacio juega un rol fundamental en la medida en que la espacialización de las contradicciones sociales contribuye a naturalizarlas, integrándolas de modo inadvertido en la cotidianeidad y disolviendo, de paso, su potencial carácter conflictivo. Tal como señalaba Lefebvre (2013), el espacio es una representación plagada de ideología, al ser un producto social cuya producción se la adjudican grupos particulares, que se apropian de un espacio para administrarlo y explotarlo. Raffestin (2012) profundiza sobre las ideas anteriores, evidenciando como la territorialidad es un proceso caracterizado por dinámicas diferentes que se dan de forma constante, progresiva y contemporánea que el autor define como territorialización desterritorialización y reterritorialización (TDR). La territorialización se considera como un momento inicial de formación de la territorialidad, mientras que desterritorialización y reterritorialización se configuran como las dinámicas de transformación de la territorialidad inicial. Como ha sido destacado por Santos, estos cambios se dan en el tiempo incidiendo sobre la cotidianidad en general, no de manera repentina. Si para Santos el factor de transformación es la técnica, para Raffestin es el trabajo. La desterritorialización, entonces, es el trabajo que va a modificar la territorialidad inicial, mientras que la reterritorialización es el trabajo que concurre a crear una nueva territorialidad. La reterritorialización, en general, se da cuando todavía está en curso el proceso de desterritorialización; esto implica que las modificaciones sobre la cotidianidad no se dan bruscamente, lo cual puede facilitar procesos de adaptación y de construcción de un sentido común favorable a los intereses de las élites. A su vez, el autor, evidencia que, en algunos casos específicos, la desterritorialización y la reterritorialización se presentan como procesos cuyas diferencias resultan bien marcadas: es el caso de acontecimientos disruptivos que transforman en profundidad el territorio como las guerras, los terremotos o los incendios. Estos acontecimientos pueden ser aprovechados por grupos económicos dominantes para reconstruir el territorio desde su perspectiva y redefiniendo su rol hegemónico, como se detalla en el artículo para el caso de Constitución.

Las consideraciones anteriores, evidencian que el territorio es una construcción social dada por las relaciones de poder entre diferentes actores territoriales y éstas son determinantes en la definición del uso de los recursos naturales. En relación a esto, asume un valor significativo la lectura territorial del concepto de hegemonía que plantea Sevilla (2014). En particular, este concepto resulta relevante para entender las estrategias de control de la cotidianidad y cómo estas influyen sobre la territorialización. El autor evidencia como 
una característica determinante de la hegemonía es la aplicación, por parte de las élites, de una pedagogía orientada a la construcción de un sentido común favorable a sus intereses. Aplicando este concepto al sector forestal, Farris y Martínez (2019: 28) evidencian que:

\begin{abstract}
la hegemonía territorial implica un trabajo sistemático de desactivación de posibles conflictos sociales territorializados, a través de prácticas blandas realizadas de forma directa o indirecta por el grupo social hegemónico que le permiten consolidarse como un actor imprescindible en el territorio, tanto en los aspectos económicos (por ejemplo consolidarse como el que garantiza el trabajo), sociales (financiación de actividades lúdicas/deportivas; gestión y/o donaciones a escuelas, organizaciones sociales etc.) y políticas (financiación directa o indirecta de campañas electorales)
\end{abstract}

En esta perspectiva, se va rompiendo u ocultando la dimensión política de lo cotidiano, como evidencia Swyngedouw (2011) a raíz del proceso de postpolitización de la planificación, reflexionando acerca de las visiones sobre "la naturaleza" y sus derivados como la sostenibilidad. Estos son definidos como "significantes vacíos", argumentando que significantes sin contenido, permiten la construcción de un guion que los dota de sentido. Se habla así de post-política, es decir la reconfiguración de la acción del gobierno para convertirla en una gobernanza, en la cual se invisibiliza la dirección política de las decisiones, poniendo a los stakeholders como los únicos que las pueden tomar. De esta manera, se aparenta que problemas y dificultades reconocidos como conflictivos, encuentran solución en acuerdos técnicos, a través de la producción de consensos.

Desde ahí, la territorialización y, por ende, la planificación, entendida como la modificación del orden socio-ambiental dado, deviene práctica violenta, en tanto acto de adoptar una solución y no otra, de producir ciertas relaciones socio-naturales, de traer a primer plano ciertas naturalezas en vez de otras. La cuestión es develar quién gana y quién paga, quién se beneficia y quién sufre los procesos particulares del cambio de circulación metabólica (Swyngedouw 2011).

En este punto es posible apreciar como las estrategias de gobernanza urbana se apropian del discurso de la sostenibilidad para el diseño urbano, bajo argumentos técnicos y gerenciales que justifican procesos de territorialización en mano de actores hegemónicos. En los siguientes apartados, evidenciamos cómo, en los casos de las regiones de Maule y Nuble, se ha articulado una territorialidad hegemónica, funcional a los intereses de pocos grandes holdings y desarrollada a través de un sistemático vaciamiento de la dimensión política de lo cotidiano.

\section{Territorialización empresarial en regiones forestales, entre dinámicas transescalares, hegemonía territorial y prácticas cotidianas locales.}

La expansión del sector forestal en Chile se ha dado a través de varios factores, llevados a cabo por diversos actores a diferentes escalas territoriales y temporales. Los conceptos teóricos presentados en el apartado anterior permiten una lectura de las relaciones de poder que han configurado y reconfigurado la territorialidad en las regiones forestales de Chile. La historia ambiental de los actuales territorios forestales ha sido caracterizada por cambios en la técnica que han modificado los sistemas de objetos y acciones, implicando dinámicas de desterritorialización y reterritorialización. 
La territorialidad forestal nace a partir de cambios sustanciales en la técnica, los sistemas de acciones y objetos, el trabajo, la cotidianidad. Consideramos como la territorialidad antigua aquella basada en la técnica del latifundio que implicaba un trabajo agrario orientado al cultivo extensivo de cereales, complementado por viñedos, chacras para la subsistencia cotidiana y reductos, más o menos amplios, de bosque nativo, al cual estaban asociadas funciones ecológicas, culturales y económicas. Esta multifuncionalidad productiva se expresaba en un calendario agrario que determinaba la cotidianidad y proximidad de estos territorios, en una íntima relación entre tiempo, trabajo productivo, prácticas de reproducción social material y simbólica. Derivan formas de proximidad representadas, por ejemplo, en el "mingaco" o en la "vuelta de mano", en las cuales los diferentes campesinos del territorio ponían su trabajo a disposición de quienes lo necesitaban por una labor agraria, sabiendo que los demás también solidarizarán con él si lo necesitara. En estas actividades participaban también mujeres y niños, en un ritual colectivo que, una vez terminada la faena, se cerraba con un momento lúdico que permitía estrechar los lazos sociales. Esto se enfatizaba con el calendario de las recurrencias religiosas, en un sincretismo entre la dimensión material agraria y la espiritualidad, como la Cruz de Mayo que coincidía con el inicio de la siembra del trigo (Chavarria 2009).

La desterritorialización se da con el abandono del cultivo de cereales, la venta de tierras, el parcelamiento de los latifundios y la erosión del suelo. Paralelamente a estas dinámicas, se van configurando otras de reterritorialización, en las cuales el Estado ha sido un actor determinante en redefinir acciones y objetos y, por ende, la cotidianidad. A partir de la Ley de fomento forestal del 1931 se empiezan a plantar especies foráneas, se re reconfigura la técnica y se modifica el trabajo. El DL 701/74 significa una aceleración sustancial a estas dinámicas de reterritorialización que se visualiza en el cambio en el paisaje y también en las acciones y los actores.

Más recientemente, un significativo cambio de técnica que ha influido en la territorialidad de estas regiones ha sido el proceso de certificación de la producción forestal. Esto, como señalan Carrasco (2015) y Carrasco y Salas (2016) implica una renovación del modo productivo de las empresas forestales y de su relación con el territorio en el cual desprenden sus actividades. Siguiendo el planteamiento de Santos, esto implica cambios en el sistema de objetos y de acciones. Son ejemplos de ello: los procesos participativos y productivos asociados a las estrategias de valor compartido ${ }^{1}$, la creación de casas abiertas, la construcción de viviendas y obras sociales. Estos ejemplos se pueden configurar como el desarrollo de una hegemonía territorial por parte de las empresas, que a partir de prácticas blandas impone una idea de territorio. Una profundización de este proceso de reterritorialización es representado por las estrategias de diferenciación productiva y de internacionalización favorecidas por la estructura del holding. Estas han tenido una aceleración a la luz de los incendios del año 2017 que se configuran como una desterritorialización repentina.

A continuación, se describe el proceso de territorialización operado por una de las dos

ARAUCO S.A. 2014 Gobernanza, Participación y Valor Compartido. disponible en: http://oldcedeus.blomster.cl/wpcontent/uploads/2014/08/Patricio-Eyzaguirre-Subgerente-ValorCompartido-Forestal-Arauco.pdf 
principales empresas forestales chilenas, evidenciando qué cambios en los sistemas de objetos y acciones se han producido y cómo esto implica una reterritorialización basada en prácticas hegemónicas.

\subsection{Diferenciación productiva e internacionalización de las grandes empresas forestales: la transescalaridad del holding}

En su comienzo los esfuerzos, tanto del Estado como de los privados, se han concentrado en la escala local y estatal, aunque condicionadas por la demanda internacional, y sostenida por una base ideológica de tipo "desarrollista" que asociaba la expansión de las plantaciones con el crecimiento económico. A partir de los años 2000 hubo una internacionalización profunda que significó también un cambio en la base ideológica: a pesar de que no se ha eliminado por completo el discurso "desarrollista", el sector se ha orientado derechamente hacia el concepto de "sustentabilidad", aunque con las contradicciones que señala Swyngedouw. Este cambio ha sido impulsado en primer lugar por la demanda del mercado global de productos que respondan a los requerimientos de las agencias de certificación, tanto en lo que se refiere al proceso productivo como a las relaciones entre empresas y comunidades locales, implicando un abordaje transescalar de las estrategias empresariales.

En primer lugar, hay que destacar la marcada presencia de las empresas más grandes en la inversión internacional, con adquisiciones de otras empresas.

Dentro del duopolio, Arauco S.A. está teniendo un rol protagónico, realizando inversiones importantes para posicionarse como unos de los principales grupos madereros del mundo, adquiriendo activos forestales en América latina (Argentina, Uruguay y sobretodo Brasil), en Europa y Estados Unidos. Esta capacidad de inversión es posible también gracias a la estructura del holding que permite una diferenciación de las actividades productivas y especulativas y un acceso al crédito impensable para otras empresas, permitiéndole posicionarse transescalarmente en la economía global (Farris y Martínez 2019).

Junto a esta internacionalización, las empresas, como Arauco S.A., han puesto en marcha estrategias de diversificación productiva a escala local. Desde hace unos años, aunque todavía de forma incipiente, el Instituto Forestal y la Corporación de la Madera están apoyando nuevos productos forestales, en particular no maderables (PFNM). Complementariamente, el sector privado se está orientando con cada vez mayor convicción hacia productos rurales complementarios para la creación de mayor valor añadido a través de su transformación industrial: los TRAFKINTU² de los años 2017 y 2018 han sido emblemáticos al respecto. En este proceso ha entrado significativamente la empresa Arauco S.A. con la elaboración de diferentes productos derivados, orientados a la exportación (Giménez et al. 2018).

En línea con este proceso de diferenciación productiva, se configura la incipiente expansión de la industrialización de la edificación en

Encuentro anual de los productores forestales en el cual participan mediana y grandes empresas, junto con las asociaciones de categoría e investigadores académicos. Durante las jornadas de trabajo de las ediciones 2017 y 2018, se abordó cómo el sector forestal iba a desarrollar una estrategia para el futuro, apuntando hacia la diferenciación productiva e indicando en el maqui, el pino piñonero y el quillay las especies más interesantes para un uso intensivo de tipo industrial. 
madera, a través de la Corporación de la Madera (CORMA), como cara institucional, y de Arauco S.A. y CMPC, como faceta empresarial.

Al respecto, discusiones en torno al uso de la madera como material de construcción han ganado cada vez mayor relevancia en los últimos años. Las ediciones 2017 y 2018 de la "Semana de la Madera" realizadas en Santiago, la "Primera Feria de Construcción en Madera y Sustentabilidad", realizada en Concepción en 2018, junto con un consistente número de seminarios y talleres específicos, son ejemplos significativos del interés en dar visibilidad a este material y discutir sobre sus potenciales usos constructivos.

Es interesante notar las complementariedades entre el sector forestal y el sector público institucional (el Estado en sus diferentes escalas). $\mathrm{Si}$ el primero empuja hacia la diferenciación productiva, el segundo provee garantizar (y financiar) las oportunidades para realizar los primeros modelos de este subsector totalmente incipiente.

\subsection{Lo cotidiano en disputa: la construcción de una hegemonía territorial empresarial y procesos de resistencia/adaptación social}

El proceso de diferenciación productiva presentado anteriormente, se complementa con un renovado enfoque de las estrategias de Responsabilidad Social Empresarial que se han ido refinando y complejizando desde la década del 2010, bajo el marco conceptual del denominado "Valor compartido" (Porter y Kramer 2011). Por esta razón hablamos de la construcción de una hegemonía territorial que actúa sobre la cotidianidad de la población de los territorios rurales forestales. Esta tiene su base y su capacidad de condicionamiento en la increíble masa forestal del monocultivo y se realiza a través de la conformación de redes productivas y sociales que se enfocan en proveer necesidades y servicios básicos.

Arauco S.A. expande sus áreas de influencia más allá del sector forestal, desplegando diversas estrategias y dispositivos de intervención en los territorios en los que se inserta. Esto lo hace de forma directa o a través de las diferentes Fundaciones que financia.

Para los casos que consideramos, la hegemonía se despliega a través de la red de "Casas Abiertas", financiada directamente por la empresa, las fundaciones Acerca Redes y Fundacional Educacional Arauco, la empresa Elemental y el vínculo con la consultora Tironi \& Asociados.

De acuerdo a lo declarado por la empresa ${ }^{3}$, las Casas Abiertas responden a un formato de relación con las partes interesadas, cuya finalidad es generar un espacio de encuentro y diálogo con los habitantes de las zonas en las que la empresa se inserta, buscando identificar de manera conjunta oportunidades de colaboración e ideas de mejora. Dicho formato forma parte del modelo de mejora continua de la empresa y se desarrolla de 2 maneras: Casas Abiertas Permanentes (1 en la comuna de Ranquil y 2 en la de Arauco) y Casas Abiertas Itinerantes (43 puestas en marcha en distintas comunas durante el 2018). Al rastrear su origen, encontramos que su primera versión emerge en el proceso de reconstrucción de la ciudad de Constitución, tras el terremoto del

Arauco S.A. 2018 Resumen Público Plan Maestro de Ordenación Forestal 
año 2010, modelo que con posterioridad a este acontecimiento es utilizado como instancia de dialogo entre la empresa y las comunidades, en la línea de la metodología "Gestión Abierta", propuesta por la consultora Tironi \& Asociados para la gestión de controversias.

La Fundación Acerca Redes, de acuerdo a lo declarado en su página web institucional ${ }^{4}$, consiste en una red de "HUBs" o espacios equipados que atraen y conectan capacidades, impactando en emprendimientos y desarrollo local, localizados en territorios alejados de los principales centros urbanos. Su objetivo es ofrecer un espacio de trabajo y encuentro $y$, a la vez, promover el asociacionismo entre emprendedores locales y diversos actores (productivos, técnicos, académicos, culturales, etc.), buscando acelerar procesos de innovación y emprendimiento asociativo, capaz de impactar de manera significativa en el desarrollo social. A través de esta figura, Arauco S.A. logra aglutinar fondos privados y públicos, destinándolos a proyectos que se alinean con sus objetivos productivo-territoriales.

La Fundación Educacional $\mathrm{Arauco}^{5}$, por su parte, forma parte de la empresa Arauco S.A. desde 1989 y su misión consiste en "contribuir a dar mayores oportunidades de desarrollo a niños y jóvenes, a través de la educación".

Además de las fundaciones mencionadas, el grupo Angelini, desde 2006, es accionista mayoritario de Elemental (con un $40 \%$ de las acciones), firma de arquitectura fundada por el ex coordinador del Plan de Reconstrucción Urbana del MINVU, Pablo Allard y reconocida

\footnotetext{
http://acercaredes.org

http://fundacionarauco.cl
}

por "revolucionar" el modelo de las viviendas sociales. Roberto Angelini, presidente del grupo, explica el interés hacia esta empresa por el énfasis puesto en la innovación aplicada a lo social $^{6}$. Su cara más visible y emblemática es el arquitecto Alejandro Aravena, ganador del premio Pritzker de arquitectura el 2016 y entre sus proyectos más destacados se encuentran: el conjunto de viviendas sociales de Constitución y el Centro de Innovación Anacleto Angelini de la Universidad Católica de Chile.

A su vez, tal como se ha señalado, Arauco S.A. ha mantenido una vinculación directa con la consultora Tironi \& Asociados, con quienes comienza a trabajar desde el año 2009, identificando "controversias socio-técnicas", las que son abordadas a través de la metodología "gestión abierta" basada en la realización de "foros híbridos", con el objeto de identificar e incorporar reestructuraciones tanto internas como de los tipos de relación que establece la empresa con las comunidades de los territorios donde se instala. Lo anterior, en el marco del proceso de preparación para someterse al proceso de certificación internacional Forest Stewarship Council (FSC).

La característica común de los casos que se presentan a continuación es el desarrollo de un proyecto de territorio, que se desprende a partir de la centralidad de una planta de celulosa (Constitución y Nueva Aldea). Estos proyectos se configuran como estrategias de hegemonía territorial, caracterizadas por prácticas blandas orientadas a la cohesión social y la desactivación del conflicto, posicionando a la empresa como "un vecino" con la capacidad económica y la

http://www.lignum.cl/2009/09/07/roberto-angelini-explica-las razones-del-fuerte-vinculo-entre-copec-y-elemental/ 
actitud paternalista de financiar intervenciones de desarrollo en el territorio.

\subsubsection{Estrategias sociales y económicas desarrolladas por la empresa en el territorio costero del Maule. El caso del Plan de Reconstrucción de Constitución}

La comuna de Constitución, ubicada en la región del Maule, es un territorio icónico de la trayectoria de expansión forestal en el país: como la mayoría de las comunas de la Cordillera de la Costa, más del $50 \%$ de su superficie es cubierta de plantaciones forestales (INFOR $2017^{7}$ ) y además alberga una de las primeras plantas industriales de celulosa del país. Esta industria, localizada en el centro de la ciudad, ha sido construida por el Estado en 1967 y actualmente es propiedad de Arauco S.A. Al ser, junto con la comuna de Arauco, el lugar donde nace la compañía, el territorio de Constitución es considerado por la empresa como "Comuna Fundacional", lo cual implica que desde años ha ido concentrando parte importante de los programas e iniciativas que la empresa define de "contribución al desarrollo local sustentable" (Arauco S.A. 2018: 12) y que se realiza a través del sistema de Fundaciones mencionado anteriormente.

Ejemplo paradigmático de la capacidad de territorialización de la empresa, es el rol que ha asumido después del terremoto y maremoto del 27 de febrero de 2010 que afectó significativamente a la comuna. El gobierno (primer mandato de Sebastián Piñera, 20102014), delega a la empresa la responsabilidad de liderar y financiar el Plan de Reconstrucción

INFOR 2017 Programa de Actualización Permanente de Plantaciones Forestales. Disponible en https://wef.infor.cl/ estadisticas_regionales/estadisticasregionales.php
Sustentable de la comuna de Constitución (PRES). Eugenio Tironi (2011: 13) evidencia las motivaciones, resaltando que "(Constitución) es la ciudad donde nació la empresa, hace más de cuarenta años. Ayudar a Constitución salir adelante se transformó en un deber".

El objetivo del PRES ${ }^{8}$ es establecer una cartera de proyectos que contempla la relocalización de viviendas, la delimitación de zonas de riesgo, la generación de proyectos productivos detonantes, proyectos de infraestructura y equipamiento comunitario, entre otras. En total, se realizan 28 proyectos, por una inversión de casi 67 mil millones de pesos, entre inversiones privadas y públicas, todos caracterizados por buscar imprimir un sello de "sostenibilidad" y "urbanismo resiliente" a la ciudad.

Para el diseño del PRES, Arauco S.A. contrató a Elemental, firma de arquitectura del mismo grupo Angelini, y ARUP, prestigiosa consultora multinacional de ingeniería, lo cual, "le otorgó una capacidad técnica que el Estado jamás habría logrado igualar, dándole al Plan un enfoque de largo plazo que lo convierte en un avance político único" (Tironi 2014: 5).

Tal como sehaseñalado, la respuesta desplegada tras la irrupción del terremoto se da en pleno proceso de preparación para la certificación FSC. En este contexto, Eugenio Tironi (2011), sostiene que el PRES se convierte en "otro laboratorio abierto donde se puso a prueba gran parte de los conceptos y metodologías en materia de gestión de controversias"; metodología bautizada como "Gestión Abierta", cuyo objetivo no es eliminar la incertidumbre

PRES Constitución. 2010. "Plan estratégico Sustentable". Santiago, Chile 
ni resolver o clausurar las controversias, sino alcanzar certezas provisorias que a todos los actores involucrados les resulten confiables y equitativas.

De modo que, para llevar a cabo los procesos participativos contemplados en el PRES, se replica gran parte de la metodología que se venía desarrollando durante el proceso de preparación para la auditoria de la certificación FSC. Se abrió una "Casa Abierta", ubicada en el centro de la ciudad, para servir como lugar de encuentro y canalización de la información respecto a los proyectos contemplados en el PRES, cumpliendo, a su vez, la función de espacio comunitario. Por estos atributos, representa un lugar de construcción de cotidianidad tras la catástrofe, aunque bajo el control de la empresa.

En concreto, los principios de operación del PRES se sintetizan en viabilidad (económica, política y técnica), excelencia y participación (por y con la comunidad). La sustentabilidad que proclama el Plan se refiere a una mirada holística, que permita a la ciudad adaptarse ante eventuales situaciones de riesgos futuros, es decir, pensando la reconstrucción desde la resiliencia. Al mismo tiempo, se pretende abordar la calidad de vida de la población local de una manera innovadora, con participación e ideas de la propia comunidad. En definitiva, se trataría de la puesta en práctica de un "urbanismo resiliente" entendido como un ordenamiento territorial estratégico, adaptado a las condiciones geográficas y riesgos naturales de las ciudades ${ }^{9}$. Propósito que se materializa en el Parque de Mitigación ubicado en el borde

http://www.disenoarquitectura.cl/pres-constitucion-deelemental-arquitectos/ costero de la ciudad, cuyo objetivo es a la vez aumentar la biodiversidad urbana y reducir los posibles impactos de eventuales maremotos. Se elabora, así, una narrativa post-política, en la cual sustentabilidad y resiliencia se abordan de forma complementaria y mediada a través de un proceso de gobernanza. Ésta adquiere autoridad por el protagonismo entregado a los expertos (ingenieros, arquitectos, urbanistas y geólogos) en la planificación, desactivando la dimensión política del proceso de resolución de conflictos (sobre el uso y propiedad del borde costero), bajo argumentos técnico-gerenciales que, finalmente, justifican el proceso de territorialización empresarial. Esta narrativa se alimenta con la entrega a Elemental del Premio a la Innovación Avonni 2014, en la categoría Ciudad Nueva, por el trabajo realizado en el PRES.

Esto, en la práctica, se ha caracterizado por una serie de proyectos emblemáticos como el Centro cultural, la Biblioteca Municipal y conjuntos habitacionales para trabajadores y damnificados. Estos ejemplos son espacios en los cuales se desarrolla la cotidianidad de parte importante de la población de la ciudad. No es secundario destacar que para su construcción se utilizó la madera como material predominante, reforzando el imaginario de territorio forestal y el sello de sostenibilidad que se encuentran tras las orientaciones del Plan. Cabe señalar que tanto el Centro Cultural como la Biblioteca, son gestionados por la Corporación Cultural de Constitución, figura creada para canalizar y gestionar recursos privados. Ésta está integrada por un representante de Arauco S.A., un gestor cultural municipal y actores locales vinculados a la cultura; hasta el año 2017 su presidente era el subgerente de asuntos públicos de la firma forestal. A los proyectos señalados, se suman la 
construcción de una piscina temperada, abierta a la comunidad, construida en un terreno entregado en comodato por Arauco S.A. y que utiliza la energía producida por la planta de celulosa, a través del tratamiento de biomasa, y el ya mencionado Parque de Mitigación, para cuya construcción se expropiaron y relocalizaron viviendas e infraestructuras públicas y privadas, dañadas por el terremoto y maremoto.

A su vez, las viviendas construidas forman parte del Plan de Viviendas para Trabajadores de Arauco S.A. (PVT), reconocido el año 2015 por la Cámara Chileno Norteamericana de Comercio con el premio "Buen Ciudadano Empresarial". Al respecto, la empresa destaca que esta iniciativa de valor compartido busca promover el acceso a la vivienda para sus trabajadores y las comunidades aledañas a sus actividades productivas, gestionando la adquisición de terrenos y desarrollando programas de acompañamiento técnico para la postulación a subsidios públicos ${ }^{10}$.

Estas prácticas materiales, son acompañadas por una narrativa que las sustenta ideológicamente, contribuyendo a la construcción de un sentido común favorable a la empresa. Ejemplo de ello es la publicación, a un año de ocurrida la catástrofe, del libro "Nuestro Terremoto: El camino de reconstrucción de una empresa y la comunidad después de 27/F", donde Arauco S.A. presenta su visión sobre cómo enfrentó al desastre, sintetizada claramente en la siguiente cita:

es cierto que Arauco es una empresa con fines de lucro, y que no es el Estado. Pero también es cierto que,

http://www.lignum.cl/2015/11/16/otorgan-premio-buenciudadano-empresarial-a-arauco-por-plan-de-viviendas-paratrabajadores/\# aunque sea una empresa global en el sentido de que sus productos se insertan en el mercado mundial, es quizás una de las empresas más locales, más enraizadas en la geografía física y humana de Chile. El camino para entender eso, dentro de la empresa y también fuera de ella, ha sido largo, sinuoso y difícil, y ha estado marcado por crisis anteriores al terremoto y al tsunami. Pero es un camino que se está recorriendo. $Y$ el terremoto lo demostró tal vez de la manera más brutal pero verdadera, en el sufrimiento es donde se ve qué tan de verdad es el asunto, de qué madera -y vaya que madera hay en esta historia- está hecho todo el mundo (Aravena y Sepúlveda 2011: 222).

Como muestra de esta pedagogía orientada a la construcción de un sentido común favorable al imaginario forestal, la revista especializada LIGNUM destaca que la madera ha estado presente en toda la historia de este territorio, desde su fundación como pueblo de astilleros, hasta hoy como la ciudad forestal más importante de la región. De modo que, en el proceso de reconstrucción, la madera destaca en la materialidad de la ciudad: en las casas, en el mobiliario urbano, en sus plazas y edificios públicos; imprimiendo a Constitución el sello propio de urbe forestal ${ }^{11}$, en respuesta al objetivo del PRES.

Siete años después del terremoto, Constitución se ve afectada por un nuevo desastre: los incendios forestales de enero y febrero de 2017. Ante esta nueva catástrofe, Arauco S.A. despliega un similar modo de accionar e intervenir en el territorio. Esta vez, resultaron afectadas las localidades rurales de la comuna de Constitución; entre ellas, la que más sufrió daños fue Santa Olga.

En esta ocasión, se replica la lógica de la alianza público-privada utilizada en el PRES,

http://www.lignum.cl/2015/06/10/constitucion-se-reconstruyede-la-mano-de-la-madera/ 
esta vez liderada por el Ministerio de Vivienda y Urbanismo (MINVU), alianza que aglutina inversiones de diversos actores privados, entre ellos Arauco S.A.

Con este nuevo desastre, la firma forestal se enfrenta a una nueva controversia: el cuestionamiento del modelo forestal, tras la visibilización de la evidente vulnerabilidad y dependencia de los territorios donde se emplaza el monocultivo silvícola. La empresa responde a este cuestionamiento en una primera fase, comprometiéndose con el abastecimiento de agua potable ${ }^{12}$ y la entrega de terrenos en comodato para la construcción de infraestructura pública. Luego, a través de la Fundación Acerca Redes, impulsa proyectos orientados al fomento del desarrollo local.

En una conversación sostenida durante un trabajo de campo, una persona vinculada a Acerca Redes, describe la reconstrucción postincendio como la versión mejorada del PRES, que se ha concretado a través de la acción de la Fundación en la organización de mesas de trabajo con actores públicos y privados, gestionando recursos vía ley de Donaciones e implementando los proyectos. Entre ellos, se destaca la conformación de una cooperativa de recolectoras/es en la comuna de Empedrado (colindante a Constitución e igualmente afectada por el incendio). Su objetivo es impulsar la reconstrucción productiva de la actividad de recolección de frutos silvestres, hierbas y hongos, tal como se relata en la siguiente entrevista:

"La idea es juntar productos, lo que sea, porque acá igual antes se daba la mosqueta, la mora, el maqui, y los

https://www.arauco.cl/chile/nuevo-sistema-de-agua-potablepara-santa-olga-esta-terminado/ hongos po', entonces eso... o las hierbas medicinales. Entonces que todo sirva para secado, hacer una empresa que seque todo eso, para, para después comercializarlo a través de, no se po', de empresas más grandes" (Recolectora, Empedrado, marzo 2018).

Las actividades de la cooperativa se concretan, además del propio trabajo de recolección, en la construcción de una planta de procesamientos para generar productos con el sello Fair Trade, comercio justo, además de jornadas de capacitación de mujeres emprendedoras, orientadas entre otras cosas a la comercialización, e iniciativas que buscan fomentar el turismo en localidades rurales.

También el incendio, como el terremoto/ tsunami, se configura como un evento disruptivo que implica una desterritorialización profunda y repentina que reconfigura los sistemas de objetos y acciones y, por ende, la cotidianidad. Ante acontecimientos de este tipo, empresas y población tienen capacidades desiguales para abordar la nueva reconfiguración del espacio. En el caso de Santa Olga, para muchas personas ha significado la pérdida de su pertenencias materiales y simbólicas: viviendas, infraestructura pública y lugares de trabajo. Para la empresa, un retraso en la producción y eventualmente una reducción de las ganancias, dada la destrucción de plantaciones y aserraderos. Esto ha implicado que la reterritorialización haya sido caracterizada por una condición de precariedad y dependencia de la población, y una limitada capacidad de decisión y propuesta de soluciones.

Desde esta perspectiva, la conformación de la cooperativa de recolección de hongos redefine una actividad tradicional de este territorio, realizada principalmente por mujeres durante décadas de modo informal, antes en el bosque 
nativo y ahora en las plantaciones forestales, y que ha representado una fuente de subsistencia y contribución a los ingresos familiares, tal como se evidencia en esta entrevista:

"Cuando mi mamá estaba chica hacía lo mismo que yo hacía cuando ya era más grande, y así sucesivamente, y su mamá ella se recuerda cuando ella era chica, también recolectaba los hongos para sobrevivir" (Recolectora, Empedrado, marzo 2018)

La diferencia, en términos territoriales, entre la condición anterior al incendio y la situación actual es que la empresa, a través de Acerca Redes, ejerce influencia directa en el desarrollo y formalización de la práctica de recolección:

\begin{abstract}
"Eh, es que ellos han sido como los que han gestionado [Acerca Redes] todo, todo, todo. La postulación, las capacitaciones... nos explicaba cómo, qué es lo que era una, una cooperativa, que nosotros no teníamos idea. No tenía idea yo, realmente yo no tenía idea qué es lo que era una cooperativa" (Recolectora, Empedrado, marzo 2018).
\end{abstract}

Estas dinámicas, implican una re-orientación hacia el mercado (sobretodo internacional) de una práctica productiva local y su gestión en el marco de las estrategias de intervención territorial y diversificación productiva de la empresa.

Un ulterior tipo de intervención de la forestal en el sistema de acciones de este territorio y en la cotidianidad de la población, se ha dado a través del programa "De Raíz". Arauco S.A. ha comenzado a promover y financiar la conformación y funcionamiento de la "Red de Prevención", que se articula en "Comités Locales de Prevención" constituidos en comunidades aledañas a las plantaciones. Los comités son liderados por monitores, seleccionados por Arauco S.A., cuya función principal es incentivar el involucramiento ciudadano y su concientización ante el peligro de los incendios. El objetivo que se plantean los comités es disminuir su ocurrencia en al menos un $20 \%$. La Red está presente en 90 comunas de 6 regiones del país.

Este proyecto se inserta en el trabajo pedagógico de construcción de un sentido común, favorable a los intereses corporativos. En términos ideológicos se socializa la asunción de responsabilidad respecto a un riesgo socioambiental a la colectividad que vive en el territorio. Se plantea que el riesgo involucra a todos y por tanto la tarea de prevención debe ser colectiva, ocultando así la principal critica recibida en el post-incendio: la expansión sin control del monocultivo aumenta la posibilidad de incendios y el riesgo para la población. Por otra parte, esta iniciativa al hacer protagonistas a los habitantes en tareas de fiscalización, instaura y legitima prácticas de control de lo cotidiano, enfocadas en la protección en primer lugar de intereses particulares, como el patrimonio de la empresa, y luego de lo colectivo.

Esto evidencia un rol de la población en la reterritorialización, orientada por los intereses privados. A la vez, las reconstrucciones postcatástrofe han visibilizado instancias de oposición a las prácticas hegemónicas, aunque se han revelado más bien contingentes que estructurales.

Respecto al post-terremoto, desde su puesta en marcha, en abril de 2010, el proceso participativo ha sido fuertemente criticado por la falta de participación de los ciudadanos (Salgado, 2016). Al respecto, el informe final del PRES estima una participación de 470 personas, lo que representa sólo el $1,6 \%$ del total de residente de 19 años o más (Tironi 2014).

Las principales críticas ciudadanas han sido articuladas en el Movimiento Nacional por 
la Reconstrucción Justa $\left(\mathrm{MNRJ}^{13}\right)$. Si bien sus objetivos estaban enfocados hacia una demanda por un derecho colectivo a la ciudad (Harvey, 2013), a la vez sus reivindicaciones no han apuntado directamente a incidir sobre el modelo económico-productivo que, finalmente, orienta la lógica de ocupación territorial validada con la reconstrucción. Junto a esto, la oposición parece disolverse a medida que se obtienen las soluciones habitacionales, ya sea por el desgaste propio de las organizaciones (Imilan y Fuster 2013) y/o porque las movilizaciones apuntan más a reivindicaciones individuales que colectivas. La siguiente cita da cuenta de la inclinación a la generación de respuestas individuales ante el desgaste de lo colectivo:

\begin{abstract}
"la desconfianza, porque hay muchas promesas que no se han cumplido en realidad. No las ha cumplido el SERVIU, menos las ha cumplido la Municipalidad, mucho menos el Gobierno. Decepción por todos lados en realidad, y todo lo que te han prometido nada ha llegado, y eso te va desmotivando y va, diciendo como dice el caballero ahí, o sea como dijo el caballero ahí: 'yo arreglé mi casa con mis propios medios'. Si todos tuviéramos los medios como para hacerlo, créame que no estaríamos acá, ninguno de los que estamos acá" (Dirigenta social, Constitución 2013, Imilan y Fuster 2013:18).
\end{abstract}

El caso de los incendios muestra patrones similares en las relaciones político-sociales que han marcado la dinámica de reterritorialización. Por una parte, hubo una fuerte movilización durante la emergencia - que duró varios días para frenar el fuego y prestar una primera ayuda a los damnificados, coordinada por el Movimiento "El pueblo ayuda el pueblo". Por otra, hubo un fuerte cuestionamiento al modelo forestal que se ha planteado de forma transversal.

Movimiento que aglutina a diversas organizaciones sociales desde la Región Metropolitana a la Región del Biobío, asumió la tarea de denunciar irregularidades y canalizar demandas, manteniendo una posición crítica ante el proceso que llevo a cabo el gobierno en alianza con el sector privado.

\begin{abstract}
"Yo creo que esto fue (en relación a los incendios) una pateadura a un sistema donde la gente está cabreadísima, que puede ser, incluso yo lo comenté aquí en una reunión que tuvimos con gente de las empresas semanas atrás, no sé, rabia contenida, modelo forestal que no es adecuadamente equitativo (...) pero si uno lo trata de concentrar en algo yo creo que hay un golpe para decir, ya saben que más no da más." (Representante CORMA, abril, 2017)
\end{abstract}

Sin embargo, a pesar de esta puesta en juicio del modelo y del actuar de las empresas forestales, las intervenciones de éstas en el territorio son, en general, recibidas con un espíritu de adaptación de las prácticas cotidianas locales como la opción posible para la sobrevivencia de sus territorios y sus habitantes.

\subsubsection{Un proyecto hegemónico de territorio. La ramificación empresarial forestal frente a la resistencia y adaptación del sector vitivinícola del Valle del Itata (Ñuble)}

El valle del Itata se ubica en la recién conformada $^{14}$ región de Ñuble e incluye los ocho municipios atravesados por el río que le da el nombre, entre el Valle Central y la costa. Es territorio de secano y, desde la llegada de los conquistadores españoles, se cultivó la vid. Se debe en específico a los Jesuitas el desarrollo de este cultivo y del oficio de la vinificación. El valle del Itata y la región del Maule, hasta mitad de los años Noventa, han sido los territorios donde se concentraba la mayor superficie cultivada a viñedo, en particular de la variedad "tinta país" usada para un vino popular llamado "pipeño"15. Por ello, está incluida entre las Denominaciones de Origen vitivinícolas.

14 La XVI Región de Ñuble se conforma oficialmente el 5 de septiembre de 2017 a través de la Ley $n^{\circ} 21.033$.

15 "El pipeño debe su nombre al recipiente donde se conservaba: la pipa. La pipa era un barril de madera empleado en España y desde allí, en el siglo XVIII, llegó al reino de Chile" (Lacoste et al. 2015). 
De ese entonces, desde el enfoque de la historia ambiental, se pueden individualizar varios momentos de territorialización, asociados a cambios en la técnica que ha modificado, a lo largo del tiempo, los sistemas de objetos y acciones. Considerando como momento inicial de análisis la introducción de la vitivinicultura, la territorialidad de referencia es aquella relativa al periodo jesuita, la que describe Capellá (2009) y asocia a ese territorio que denomina como la "Franja", comprendido entre el Itata y el BioBío. A partir de eso, se han sucedido diferentes dinámicas de desterritorialización y reterritorialización. Podemos destacar unas más relevantes, señaladas ya anteriormente: la expansión de la cerealicultura - que implicó la casi desaparición del bosque nativo - y luego su remplazo por el monocultivo forestal.

Cuando la cerealicultura se consolidó como la técnica hegemónica, el sector vitivinícola igualmente tuvo un rol en caracterizar este territorio: las labores vinculadas al cuidado de la vid y a la producción de vino han contribuido y contribuyen a definir la cotidianidad y el paisaje cultural del Valle. Esto se desprende también de esta cita:

\begin{abstract}
lógicas centenarias de producción agrícola que manifiestan también sentidos colectivos de mundo, relaciones y materialidades que le otorgan singularidad en el tiempo. [...] Se trata de una cosmovisión campesino-mestiza que se sustenta en un saber-hacer organizado por las etapas que establece el ciclo agrario para la producción de la uva y otros cultivos de la tierra, imprimiendo un ritmo circular marcado por las estaciones del año y las labores que allí se desarrollan, expresando en ello una particular forma de significar la propia vida junto a otros. (Bahamonde et al. 2016:16)
\end{abstract}

Son ejemplos de ello, los trabajos que los pequeños propietarios desarrollaban individualmente o de forma colectiva (como la poda o la vendimia) tanto en el viñedo como en la casa.
El trabajo de producción y venta de vino se articulaba con otras actividades de producción económica y de reproducción social: el oficio de la tonelería; el cultivo extensivo de cereales, las chacras familiares con papas, legumbres y hortalizas; la cría de animales de corral; la recolección de frutos silvestres; la gastronomía popular o las fiestas tradicionales (como la "trilla de yegua suelta"). Esto ha implicado que la territorialidad de ese momento, si bien estaba caracterizada por una técnica dominante, implicaba a diferentes actores que construían una cotidianidad y proximidad compleja, ahora, en parte, desaparecida.

A partir de los años Ochenta del siglo pasado, la producción de vino en el Valle ha empezado una drástica reducción hasta la segunda década de los años dos mil, lo cual ha implicado una reconfiguración territorial, a través de nuevas dinámicas de desterritorialización y reterritorialización. Los principales cambios en los sistemas deacciones yobjetos locales derivan de dinámicas que se desarrollaron a diferentes escalas: estatal/global y local. En cuanto a las escalas estatal y global, la introducción masiva de variedades de origen francés (Merlot, Cabernet Sauvignon, Chardonnay, etc) en los valles de las regiones centrales del país, las innovaciones en las técnicas enológicas y los cambios en los gustos alimentarios han significado un franco retroceso de la demanda de vino pipeño. A estas transformaciones, los miles de productores del valle han mostrado una dificultad para adecuarse a la nueva demanda.

\footnotetext{
"Antes la gente tenía las parras, las vides y qué pasaba? La gente empezó con la obsesión y le echaban mucho agua al vino...se empezó a correr la voz y la gente no les compró más vino....al finales de los setenta empezó esto...
} 
Qué pasó? La gente ya no le veían un buen negocio en el vino y empezó a vender la uva. Acá se fue quedando se fue quedando. Prefería vender la uva que era la misma empresa grande a comprarla." (Vitivinicultor, Coelemu, agosto 2016)

Esto ha implicado una dinámica de desterritorialización que ha significado un cambio sustancial en la cotidianidad del territorio: de un modelo productivo enfocado principalmente en el cultivo de la vid para su transformación (vinificación) a otro orientado a la producción y venta sólo de materia prima (uva) para las grandes empresas del Chile Central.

En este contexto de cambio, se inserta otra dinámica que ha condicionadolaterritorialidad de este espacio, directamente desde la escala local: la expansión del monocultivo forestal. Desde finales de los años setenta, y particularmente desde los años Noventa, el crecimiento de las plantaciones silvícolas ha ejercido sobre la vitivinicultura una significativa presión, siendo la principal causa de erradicación de viñedos para su sustitución con pinos o eucaliptus. Esta dinámica, junto con el envejecimiento de la población activa, ha implicado una marginación de las producciones vinícolas de la zona, como evidencia esta entrevista:

\footnotetext{
"Después que pasó? El precio de la uva empezó a bajar. A finales de los Ochenta el precio de la uva bajó mucho. A finales de los Noventa el precio era muy bajo. Allá empezó el boom de los pinos. Empezó a plagarse de pinos. El precio de la uva estaba bajo entonces la gente empezaba a dar de baja las vides y a plantar pinos y hoy en día se ven las consecuencias: se ven muchos más pinos y somos muy pocos los que estamos vinificando". (Vitivinicultor, Coelemu, agosto 2016)".
}

Un factor a considerar para entender la expansión forestal en este territorio es que el valle del Itata se encuentra entre dos de los más antiguos polos industriales de celulosa de
Chile (Constitución y Arauco) de propiedad de Arauco S.A. Junto a esto, en los años Noventa, la misma empresa construye otra planta de celulosa en la comuna de Ranquil, en medio del Valle. Este proyecto ha causado varias protestas, en la misma comuna y sobretodo en las colindantes. Si bien la movilización no ha logrado parar la construcción, ha evitado que la planta productiva se llamara "Itata", optando a final por "Nueva Aldea", como el asentamiento que se encuentra cerca de la fábrica.

Entonces, este territorio, desde los años setenta, ha sido sometido a un proceso intensivo de desterritorialización y reterritorialización, transformándose de orientado a los cereales y la vitivinicultura a la silvicultura y la industria de la celulosa.

La respuesta de la población local a estas transformaciones se ha dado generalmente en un proceso de adaptación, tanto respecto a la caída del precio de la uva como a la expansión de las plantaciones forestales. Al respecto, un factor significativo ha sido la aceptación, tácita o manifiesta, de la industria forestal por parte de los viñateros. Durante el trabajo de campo se ha podido comprobar como la mayoría de los viñedos están rodeados de pinos y eucaliptus o las propiedades en las cuales están insertos poseen una parte plantada con especies forestales.

En muchos casos, la plantación forestal ha sido una alternativa para superar las dificultades del mercado vinícola. Las sociedades forestales, por una parte, se han aprovechado de la debilidad económica de los viñateros para expandir la "frontera" en una zona dedicada a otra actividad, además proponiéndose como un "salvavidas" frente a la crisis. 
A pesar de esto, en los últimos 10 años se ha producido un nuevo cambio, aunque lento y parcial, a esta tendencia: se está reorientando la producción vitivinícola. Esto se ha dado por diferentes patrones: recambio generacional, apertura a la innovación, trabajo de valorización por parte de enólogos. Estas dinámicas han significado la definición de un producto con una clara matriz territorial, renovando en términos cualitativos y estéticos el denominado vino "pipeño" y creando la marca de vinos patrimoniales y ancestrales. Este resultado ha sido posible gracias a un trabajo colaborativo, aunque siempre sujeto a tensiones entre productores por la dificultad de operar en conjunto, como evidencia la presencia de diferentes asociaciones de productores.

Esta nueva transformación del Valle no resulta exenta de contradicciones y tensiones internas, entre quienes, al alero de enólogos portadores de una cultura técnico-profesional, renuevan la producción tradicional y quienes se resisten al cambio y siguen manteniendo las prácticas tradicionales basadas en la experiencia cotidiana del campo. Como señalan Bahamonde et al. se ha ido configurando:

Un discurso que recupera la noción de patrimonio en el campo de la vitivinicultura tradicional, relevando los tipos de cepas y su arraigo temporal, pero invisibilizando a los sujetos reales: viñateros, toneleros, familias y comunidades que por generaciones han sostenido estilos productivos y relaciones socio-simbólicas que cobijan identidades en continua reelaboración (Bahamonde et al. 2016: 25).

En este contexto, en que los territorios vitivinícolas están atravesados por diferentes tensiones, se inserta la empresa Arauco S.A. Ésta, desde el 2010, ha implementado acciones de "buena vecindad" a través de una "Casa Abierta" fija, emplazada en el casco histórico de la comuna, donde está la planta industrial.
En línea con estas acciones, recientemente la empresa ha puesto su atención sobre el sector vitivinícola del Itata. El proyecto planteado por la firma forestal se ha ido configurando de a poco, desarrollándose complementariamente a las otras inversiones y proyectos sociales activados en el territorio del Itata. Empezó en 2007 con la adquisición de una parte de la histórica Hacienda Cucha Cucha de la familia Giner, unos empresarios del sector vitivinícola y hotelero. La hacienda, considerada la más antigua viña existente en Chile, fue fundada por los Jesuitas en la segunda mitad del siglo XVII. Hasta aproximadamente el 2014, Arauco S.A. ha mantenido la misma producción de la antigua gestión. A partir de ese momento, con la contratación de un destacado gerente vinícola, la empresa empieza a dar forma a un ambicioso proyecto de reconfigurar no sólo la viña, sino que todo el Valle. En este proyecto se explaya la influencia de la firma y su hegemonía territorial que permite desarrollar un proyecto en beneficio de las comunidades con las cuales entra en relación y, a la vez, generar beneficios económicos por ella misma.

Según lo declarado por el mismo gerente de Viña Cucha Cucha ${ }^{16}$, esto nace como un proyecto social inspirado en la idea de "Valor Compartido": ayudar a los viñateros del valle a no abandonar el rubro, a causa de la presión generada por los bajos precios de la uva y por la dificultad de colocar su vino en el mercado. En estos primeros años, el proyecto se ha enfocado en involucrar a los vitivinicultores, discutiendo con ellos y tratando de convencerles que la valorización del Itata puede ser una ventaja para todos, grandes y pequeños actores.

16 Soto, M. (10 diciembre 2015) "Devolviendo la mano al Valle". Revista Capital. Disponible en https://www.capital.cl/devolviendola-mano-al-valle/ 
Se han seleccionado los productores con productos cuya calidad resultase más viables en el mercado, entregándoles capacitación profesional para desarrollar una vinificación más conforme a los estándares comerciales, apoyo para la comercialización (desde el etiquetado, embotellamiento, venta) y creación de un centro de acopio para poder negociar más favorablemente con los poderes compradores.

Este trabajo se ha visibilizado a través de la apertura, en 2016, de un punto de venta en el municipio de Ranquil, justo al lado de la Casa Abierta de Arauco S.A., en una vieja casona que mantiene la firma forestal. En esta tienda se promocionan los vinos del valle, de productores que han aceptado formar parte de este proyecto y que venden sus productos al precio que ellos establecen. La tienda trata de reflejar la variedad vinícola y la diferenciación territorial, del Valle; se complementa la venta de vinos con otros productos de la zona (jabones, mermeladas, miel, etc.) o de la empresa (aceite, jugos de maqui etc.).

El acompañamiento mediático de este proyecto, realizado por los principales medios de comunicación, ha centrado la mirada en el enfoque social. Desde este punto de vista, es significativo un artículo publicado por una revista económica que titulaba "Devolviendo la mano al Valle"17 y en el cual se enfatiza como "Celulosa Arauco, con amplias inversiones forestales en Itata busca ahora recuperar el tesoro vitivinícola de esa zona, donde nació el vino chileno". Aunque de forma muy indirecta, en el artículo se evidencia un cierto malestar de la población del valle por la expansión forestal y la presencia de la planta de celulosa y, por esta

\footnotetext{
Ver nota 16.
}

razón, la inversión de la firma sería una suerte de compensación por los problemas ocasionados. Reportajes de este estilo han aparecido en los tres años siguientes, construyendo el imaginario de la empresa como artífice de un rescate de la vitivinicultura.

Esta retórica ha ocultado una parte relevante de la historia del proceso de revalorización del patrimonio territorial del Valle. El retorno de este territorio en el interés nacional se da por el esfuerzo, como se ha señalado anteriormente, de múltiples actores locales a través de diferentes estrategias de valorización de las cepas típicas de esta zona.

Si bien es indudable que el proyecto "Cucha Cucha" tiene una componente "social" y una recaída positiva en el territorio, a la vez, la componente empresarial es extremadamente relevante, o determinante. Un artículo publicado en junio de $2018^{18}$ aclara la visión de largo plazo de la empresa. Se evidencia la apuesta de Arauco S.A. de transformar el Valle del Itata en el nuevo Colchagua ${ }^{19}$, detallando las inversiones que se pretenden realizar y cómo estaría involucrado directamente en ello el principal accionista del holding, Roberto Angelini. El plan es transformar el Valle en un atractivo turístico internacional, aprovechando sus características geográficas que lo conforman "como la Toscana" chilena, con sus lomas, viñedos y pinares. El centro de este proyecto será la Viña Cucha Cucha, transformada en resort de alto estándar y

18 Esturillo J. (15 junio 2018) El plan del grupo Angelini para hacer del valle del Itata el nuevo Colchagua. En Diario Financiero http://www.df.cl/noticias/empresas/empresas-y-startups/ el-plan-del-grupo-angelini-para-hacer-del-valle-del-itata-elnuevo/2018-06-15/173052.html

19 Valle vitivinícola de la región de O' Higgins, aproximativamente a 100 kilómetros al sur de Santiago de Chile. 
bodega de vinos Premium, conectada a una red de puntos de interés turístico (alojamientos, posadas, puntos de venta de productos locales) y patrimonial (viñas y viñedos, bosque nativo, plantaciones, patrimonio histórico material e inmaterial etc.) y capaz de atraer visitantes aprovechando la cercanía con el puerto de Talcahuano (cruceros), el área metropolitana de Concepción con su aeropuerto y la ciudad de Chillán y la Ruta 5 .

\section{Conclusiones}

A lo largo del artículo hemos planteado una lectura geopolítica de la cotidianidad en las regiones forestales, mostrando el interés de algunos agentes para influirla o controlarla en su proceso de territorialización de estos espacios. A partir del análisis de este proceso, podemos proponer unas respuestas a las preguntas iniciales: 1) ¿Cómo se pueden conectar las escalas/espacios/agentes geopolíticas en la investigación? y 2) ¿Cómo se puede investigar la geopolítica del Estado y la geopolítica de la cotidianeidad?

Podemos evidenciar tres factores determinantes en laterritorialización de las regiones forestalesque ponen en relación las dos preguntas: la estructura del holding; el rol del Estado en fomentar el sector de forma directa o indirecta; el interés empresarial por incidir sobre la cotidianidad territorial y las respuestas locales. Estos factores se vinculan mutuamente, interpretándolos a través de las categorías analíticas de la transescalaridad y la hegemonía territorial.

El análisis del primer factor entrega una respuesta a la primera pregunta: la estructura del holding permite conectar la pluralidad de escalas/ espacios/agentes que caracterizan el sector forestal. Las empresas forestales desarrollan sus estrategias de manera transescalar. En primer lugar, están enfocadas en las exportaciones que responden a la demanda del mercado a escala global. Éstas, a la vez, determinan transformaciones a escala estatal y local, como las derivadas por la implementación del proceso de certificación sustentable. Las estrategias de internacionalización y diferenciación productiva, descritas en el artículo, evidencia la capacidad de posicionamiento a diferentes escalas del holding. La multiplicidad de empresas con intereses en áreas distintas que componen el grupo le permite su anclaje y su capacidad de condicionamiento espacial, ya que se posicionan como indispensables para cubrir gran parte de las necesidades económicas de los territorios en los cuales esta estructura se va ramificando.

La conexión entre el primer y el segundo factor, se hace posible también gracias al apoyo directo e indirecto del Estado. Esto se ha dado en los diversos momentos que han marcado el sector forestal, los cuales se han caracterizado a través de diferentes dispositivos aplicados por el Estado para fomentar la silvicultura industrial. Se han, así, creado las bases económicas, ideológicas y legales para la conformación actual del sector. En términos ideológicos, ya con la Ley del 1936 se propone un cambio radical en la forma de ver el bosque, pasando de ser un recurso natural aprovechado por el hombre a un cultivo completamente creado por el hombre (Camus 2006), dando vida a un proceso de producción y comodificación de la naturaleza (Castree 2003). El DL. $701 / 74$ pone alas a la expansión exponencial de las plantaciones forestales y a la sustitución del actor público por el privado. En este caso también es evidente como la capacidad coercitiva del Estado se orienta 
al beneficio de una determinada clase social y ciertos grupos económicos. El proceso de concentración de la propiedad y de la producción maderera en un restringido oligopolio confirma esta contribución imprescindible del Estado en la explotación del monocultivo forestal. Finalmente, en la última década, se ha dado un fomento indirecto al sector, implementando un modelo de gobernanza en que la empresa se hace cargo de la planificación territorial como ha mostrado el caso del PRES y el actual impulso a la construcción en madera.

La relación entre los dos factores anteriores es determinante para entender el tercero: la transformación del territorio local y el control sobre la cotidianidad.

Como se puede entender, la inserción de millones de nuevos "objetos" (los pinos y los eucaliptus, las plantas de celulosa, aserraderos, etc.) han transformando no sólo el paisaje sino la cotidianidad y la proximidad de estos territorios, redefiniendo inevitablemente la estructura social. En efecto, estos territorios, sufriendo la imposición del monocultivo forestal, han sido, en palabras de Raffestin, desterritorializados y reterritorializados, bajo los intereses de grupos hegemónicos, sometiendo a grupos subalternos a una resignificación de sus prácticas cotidianas, en la medida en que su relación con el territorio es constantemente recodificada. Es así que las plantaciones se naturalizan como parte del paisaje, son reconocidas como "bosques" y ante los ojos de los habitantes pareciera que siempre han estado ahí, dificultando o imposibilitando la visualización de alternativas de desarrollo para estos territorios. Para el caso de Constitución resultan más marcadas las acciones orientadas a subsanar necesidades de servicios básicos, como la vivienda, y desarrolladas a través de dispositivos de tipo pedagógico social, activados y sostenidos a través de la "Casa Abierta"; enfocadas en crear un imaginario de la sustentabilidad centrado en la madera, orientadas al reposicionamiento de la empresa después de dos eventos traumáticos como el terremoto del 2010 y el incendio del 2017. Los desastres, en tanto eventos disruptivos permiten: 1) la consolidación de una nueva imagen corporativa, bajo la figura del "buen vecino", 2) la posibilidad de experimentar en la construcción en madera, 3) reconstruir la ciudad en términos materiales y simbólicos y 4) legitimar la presencia de la empresa en el territorio, en especial la presencia de la planta de celulosa en el centro de la ciudad, localización que fue cuestionada durante el proceso participativo del PRES. Para el caso de Constitución, la metodología empleada para el enfrentamiento del desastre buscó poner en la mesa controversias que hasta el momento no habían sido discutidas, convocando para ello una pluralidad de actores presentes en el territorio. Es en este contexto que se discute por primera vez la localización de la planta de celulosa en el centro de la ciudad y los impactos que ello conlleva. A la vez, la tecnificación de la planificación y la escasa participación muestran un vaciamiento de la dimensión política del conflicto.

Esta asunción de tareas de planificación se evidencia también en el segundo caso estudiado. El plan de Arauco S.A. para el valle del Itata es un proyecto de territorio gestionado desde una perspectiva empresarial. Se inserta en la lógica del "Valor Compartido", interceptando una nueva transformación que la gente de este territorio está tratando de realizar, entre dificultades y contradicciones. Si bien a ello no se ha expresado una oposición o resistencia explícita, la sensación que emerge después del trabajo en terreno es que los múltiples 
actores menores de este territorio adaptarán su cotidianidad a los intereses de la gran empresa, aunque sin renunciar a sus pequeños proyectos locales o a su cosmovisión campesino-mestiza. Este caso, además, evidencia como la empresa, más que producir economía de escala, se enfoca hacia la multifuncionalidad, a través de las acciones de Valor Compartido. Éstas, que no tienen una naturaleza exclusivamente económica sino también social, explican cómo Arauco S.A. visualiza la cotidianidad local como un espacio a ocupar. El saber hacer del territorio -la recolección y la vitiviniculturason apropiados y reconfigurados a través de una narrativa que impone la firma forestal como el agente único capaz de hacerse cargo de su puesta en valor. Esta es, justamente, la expresión de la hegemonía territorial.

Los resultados de la investigación nos inducen a cuestionarnos también respecto a otras de las preguntas contenidas en este dossier:

¿Si el espacio es un producto político, es posible pensar en un espacio que surja desde una política que considere lo cotidiano como sujeto social protagonista (desde las prácticas y las vivencias de la ciudadanía)?; ¿Es posible proyectar el espacio cotidiano como un articulador de espacios de resistencia?

Respecto a estas interrogantes podemos plantear algunas hipótesis.

Ante este escenario de hegemonía territorial, el conflicto parece disolverse ante el supuesto consenso y lo cotidiano pierde su dimensión política. Los casos estudiados, parecen dar cuenta de procesos de adaptación y reinvención local ante la imposición de un modelo territorial empresarial que tiende a colonizar espacios y formas de vida cotidiana de los territorios ocupados. Esta adaptación induce a una reflexión sobre la idea de resiliencia, tensionando la visión que se propone a través del PRES.

Resulta sugerente plantear una resiliencia territorial como un proceso complementario a la hegemonía territorial. $\mathrm{Si}$, por una parte, las estrategias de hegemonía implican un despliegue de prácticas que han inducido a la expansión casi irrefrenable de las plantaciones forestales sin encontrar una significativa resistencia, la resiliencia reflejaría la adaptación a esta expansión, cuyo crecimiento exponencial en los años Ochenta y Noventa puede bien considerarse un shock territorial.

Hegemonía y resiliencia se podrían, entonces, considerar dos caras de la misma medalla. Las estrategias hegemónicas se han aplicado en contextos fecundos, caracterizados por un ambiente político favorable, una fragilidad económica evidenciada por la necesidad de suplir a las necesidades básicas y por un evidente desequilibrio en las relaciones de poder entre los actores territoriales. La resiliencia, por otra parte, se ha caracterizado por una débil crítica al modelo capitalista por parte de los actores territoriales y una constante adaptación a los cambios del mercado en búsqueda de la mejor rentabilidad en el corto plazo.

La reflexión final gira en torno al rol que ha desempeñado el Estado otorgando garantías y atribuciones al privado, a la vez que se retrae de sus funciones.

¿Es posible la reconfiguración del Estado para que sea capaz de asumir funciones contrahegemónicas en la construcción territorial de la cotidianidad? 


\section{Bibliografía}

ARAUCO S.A. 2018 Resumen Público Plan Maestro de Ordenación Forestal. Disponible en: https://www.arauco.cl/ chile/wp-content/uploads/sites/14/2019/06/EG17.2-RESUMENPUBLICO-PLAN-MAESTRO-PMOF-2019-final.pdf (consultado noviembre 2018)

ARAUCO S.A. 2014 Gobernanza, Participación y Valor Compartido. Disponible en:

http://oldcedeus.blomster.cl/wp-content/uploads/2014/08/

Patricio-Eyzaguirre-Subgerente-Valor-Compartido-ForestalArauco.pdf (consultado diciembre 2018)

Aravena, F. y Sepúlveda, A. 2011. Nuestro terremoto: el camino de reconstrucción de una empresa y la comunidad después del 27/F. Santiago de Chile: Ediciones B grupo Z.

Atienza, M. Lufin, M. Paredes, D. 2015. "La Concentración Económica y del Ingreso en Chile". Informe Anual de Avance de la Descentralización Chile 2015, Hernández, P., Hidalgo V., Sepúlveda, M.A. (Eds.). Santiago de Chile: Políticas y Estudios SUBDER: 11-28

Bahamonde, M; Mariángel, P. y Hernández M.V. 2016 Viñas y toneles del Itata. Tomé, Chile: Ediciones CETSUR.

Camus, P. 2006. Ambiente, bosques y gestión forestal en Chile. Santiago de Chile: LOM.

Canals, M. 2014. Los trabajadores forestales de la VIII Región. Condiciones de vida y horizontes políticos, 1990-2013. Tesis de grado Licenciatura en Historia, Universidad de Chile, Santiago.

Capellá, H. 2009 "Por los caminos de la identidad y del desarrollo regional". Atenea (Concepción), (500), 75-90.

Carrasco, N. 2015. "Pueblos indígenas y biodiversidad en el capitalismo contemporáneo. Propuesta para el estudio etnográfico de los procesos de certificación forestal en Chile". Justiça do Direito, 29 (1): 88-107.

Carrasco, N. y Salas, R. 2016. "Inflexiones y dilemas ético políticos del capitalismo en el Centro Sur de Chile. A propósito de la globalización forestal”. Revista Izquierdas 27: 105-123.

Castree, N. 2003 "Commodifying what nature?" Progress in Human Geography 27: 273-297

Chavarria, P. 2009 Los cogollos del viento. Concepción, Chile: Impresos Diario del Sur.

Esturillo J. "El plan del grupo Angelini para hacer del valle del Itata el nuevo Colchagua". Diario Financiero, 15 junio 2018. Disponible en: http://www.df.cl/noticias/empresas/empresas-ystartups/el-plan-del-grupo-angelini-para-hacer-del-valle-del-itatael-nuevo/2018-06-15/173052.html (consultado diciembre 2018)

Farris, M. y Martínez, O. 2019 "El capitalismo del holding transnacional en el sector forestal chileno: la consolidación de una hegemonía territorial". Revista Izquierda 45: 23-50.

Fazio, H. 2016. Los mecanismos fraudulentos de hacer fortuna: mapa de la extrema riqueza 2015. Santiago de Chile: LOM Ediciones.

Fazio, H. 2005. Mapa de la extrema riqueza al año 2005. Santiago de Chile: LOM Ediciones.

Giménez, I. M., Carrasco Henríquez, N. Y Aliste, E. (2018) Frutos en disputa: mercantilización de la silvicultura y gastrogénesis en la Baja Frontera de Nahuelbuta (Chile). Boletín Asociación de Geógrafos Españoles, 79: 1-38.

Harvey, D. (2013). Ciudades rebeldes. Del derecho a la ciudad a la revolución urbana. Buenos Aires: Ediciones Akal.

Imilan, W., Fuster, X. (coord.) (2013). Terremoto y tsunami post 27F: El caso de Constitución, Arauco y Llico. Informe del Observatorio de la Reconstrucción. Santiago de Chile: Instituto de la Vivienda, Universidad de Chile.

INFOR (2017) Programa de Actualización Permanente de Plantaciones Forestales. Disponible en https://wef.infor.cl/ estadisticas_regionales/estadisticasregionales.php (consultado diciembre 2018)

Lacoste, P, Castro, A, Briones, F, y Mujica, F. 2015. "El pipeño: historia de un vino típico del sur del Valle Central de Chile". Idesia (Arica), 33: 87-96

Lefebvre, H. (2013) [1974]. La producción del espacio. Buenos Aires: Capitán Swing,

Porter, M. E. y Kramer, M. R. 2011. "La creación de valor compartido: cómo reinventar el capitalismo y liberar una oleada de innovación y crecimiento". Harvard Business Review, 89: 31-49.

Prado, J. A. 2015 Plantaciones forestales. Más allá de los árboles, Chile. Santiago de Chile: Colegio de Ingenieros Forestales A.G.

Raffestin, C. 2012 "Space, Territory, and Territoriality" Environment and Planning D: Society and Space 30: 121-141

Salgado, M. 2016. "El desastre como acontecimiento: desenlaces y oportunidades tras el terremoto y maremoto del 27 de febrero de 2010". Reflexiones sobre la emergencia. Territorio, vivienda e institucionalidad en contextos de desastres socioambientales. Rivas, A (ed.). Santiago de Chile: Fundación Vivienda.

Santos, M. 2000 La naturaleza del espacio: técnica y tiempo, razón y emoción. Madrid: Ariel

Sevilla, A. 2014 "Hegemonía, gubernamentalidad, territorio. Apuntes metodológicos para una historia social de la planificación". Empiria: 49-72

Soto, M. "Devolviendo la mano al Valle". Revista Capital, 10 diciembre 2015. Disponible en https://www.capital.cl/ devolviendo-la-mano-al-valle/ (consultado diciembre 2018)

Swyngedouw, E. 2011 "iLa naturaleza no existe! La sostenibilidad como síntoma de una planificación despolitizada". Urban: 41-66

Tironi, E. 2011. Abierta. Gestión de controversias y justificaciones. Santiago de Chile: Aqbar Ed.

Tironi, M. 2014. "Disastrous Publics: Counter-enactments in Participatory Experiments" Science, Technology \& Human Values. 1-24

Undurraga, T. 2014 "Rearticulación de grupos económicos y renovación ideológica del empresariado en Chile 1975-2012: la paradoja de la concentración". Grupos Económicos y Mediana Empresa Familiar en América Latina. Monsalve Zanatti, M (ed.) Lima: Universidad del Pacífico 
